\title{
Prevalence of malignant uterine pathology in utero-vaginal prolapse after vaginal hysterectomy
}

\author{
(1) EDGARDO CASTILLO-PINO ${ }^{1}$, (1) VALENTINA ACEVEDO ${ }^{1}$, (1) NATALIA BENAVIDES ${ }^{1}$, (1) VALERIA ALONSO ${ }^{1}$, \\ (1) WASHIGNTON LAURÍA
}

\begin{abstract}
1Department of Obstetrics and Gynaecology, Urogynaecology and Pelvic Floor Unit, School of Medicine, University of the Republic, Hospital de Clínicas "Dr. Manuel Quintela", Montevideo, Uruguay

2Department of Obstetrics and Gynaecology, School of Medicine, University of the Republic, Hospital de Clínicas “Dr. Manuel Quintela”, Montevideo, Uruguay
\end{abstract}

\section{ABSTRACT}

objective: The aim of this study was to establish the prevalence of malignant uterine pathology after vaginal hysterectomy (VH) due to asymptomatic uterovaginal prolapse.

Materials and Methods: A descriptive observational cross-sectional study including 110 women with VH indication for hysterocele greater than or equal to POP-Q stage II with negative Pap smear still valid, and with normal transvaginal ultrasound in the past year. Patients with abnormal uterine bleeding or suspected premalignant or malignant uterine disease were excluded. All participants signed an informed consent document. The mean age was 64 year old (SD \pm 8.84 ), 85.5\% of them being menopausal.

Results: 78.2\% of histopathological findings did not present any uterine pathology. Endometrial hyperplasia without atypia was found in 11 cases (10\%) and endometrial polyps without atypia in 12 cases (10.9\%). There were no cases of hyperplasia with atypia. Uterine leiomyoma (25.5\%) and focal and diffuse adenomyosis (23.6\%) were also found. Only one case had endometrial cancer (0.9\%) and there were no cases of cervical cancer.

Conclusion: The risk of uterine malignancy after $\mathrm{VH}$ due to utero-vaginal prolapse is low. This result may have been affected by the assessment in the year prior to surgery, in keeping with recommendations of ruling out abnormal uterine bleeding and considering Venous thromboembolism (VTE) assessment and cytology of the cervix in the preoperative period. Information regarding the risk of premalignant and malignant pathology of the uterus must be included in the pre-surgery information in the form of a consent document.

Keywords: Pelvic organ prolapse; utero-vaginal prolapse; vaginal hysterectomy; uterine preservation; risk of malignancy

\section{INTRODUCTION}

Pelvic organ prolapse (POP) is a common health problem ${ }^{1}$ affecting 30 to $50 \%$ of women, ${ }^{2,3}$ and its prevalence increases with age and parity. ${ }^{4}$ Its incidence continues to increase as a result of the aging of the world's populations and higher rates of obesity in some populations. ${ }^{4}$ POP has a negative impact on quality of life of women and it is associated with physical, psychological and sexual problems. ${ }^{5}$

Address for Correspondence: Edgardo Castillo-Pino, Department of Obstetrics and Gynaecology, Urogynaecology and Pelvic Floor Unit, School of Medicine, University of the Republic, Hospital de Clínicas "Dr. Manuel Quintela", Montevideo, Uruguay

E-mail: castillopino@gmail.com ORCID ID: orcid.org/0000-0003-0241-9625

Received: 25 May 2019 Accepted: 15 October 2020

${ }^{\circ}$ Copyright 2020 by the International Society for Pelviperineology / Pelviperineology published by Galenos Publishing House. 
Pelvic floor repair surgery is the main therapeutic tool for POP treatment. One of its surgical treatment options is vaginal hysterectomy (VH). The vaginal approach facilitates anatomical entry into the perineum and pelvis, resulting in easy access for the repair of vaginal relaxation. Once pelvic floor reconstruction surgery through the vagina has been defined, the surgical tactic should be selected considering the preservation or exeresis of the uterus. ${ }^{6}$ This tactic should be planned with the aim of restoring normal anatomy and adequate support of the vaginal walls and apex.

Utero-vaginal prolapse (UV-POP) is the primary indication for most VHs in Uruguay, ${ }^{6,7}$ and worldwide. ${ }^{8,9}$ At present, $\mathrm{VH}$ is one of the most commonly performed surgical procedures to treat UV-POP and, generally, it is combined with other pelvic floor reconstruction procedures. ${ }^{10}$ Hysterocele is usually accompanied by other conditions, such as cystocele, enterocele, rectocele, or relaxation of the pelvic floor. All these conditions must be corrected in the same surgical procedure. Tissue laxity facilitates the performance of hysterectomy through the vagina.

The vaginal removal of the uterus has a very long history, and references have been found, for instance, to conditions in which it had to be removed-in whole or in part-in Soranus of Ephesus, who reported that some authors indicated that it should be removed when the prolapsed uterus was of a blackish hue. ${ }^{11}$ Since the first regulated VH was performed in the nineteenth century, ${ }^{12} \mathrm{VH}$ has been both revered and discredited, but it is still around today.

The reasons for preserving the uterus in women with UV-POP may be the patient's request or the gynaecologist's conviction about the advantages and disadvantages of conservative management. ${ }^{13-15}$ Some authors argue that UV-POP is the result rather than the cause of POP, and hysterectomy associated with dissection of the pelvic floor could increase complications. ${ }^{14,15}$ Other authors have voiced their concern about the possibility of undiagnosed pathologies or the risk of developing future diseases, such as cancer, if the uterus is not excised. . $^{16,17}$

The dissenting opinions in this regard make it necessary to have open discussion with the patient about the pros and cons of hysterectomy or hysteropexy, so that the final decision would be informed, conscious and consensual.

The aim of this study was to establish the prevalence of malignant and premalignant uterine pathology in the histopathological findings in patients who have undergone VH due to UV-POP in a sample of women in our area.

\section{MATERIALS AND METHODS}

A cross-sectional descriptive observational and prospective study was carried out. Patients seeking consultation who were assisted by the Pelvic Floor Unit medical team between April 1, 2017, and March 31, 2019, were selected. The study was approved by the Ethics Committee of the Hospital de Clínicas of Medical School of Montevideo, University of the Republic. All the participants signed a consent document after being briefed about the study.

The sample included patients with asymptomatic prolapsed uterus greater than or equal to POP-Q stage II with an oncological cervical cytology study with negative Pap stain two years prior to $\mathrm{VH}$ and with normal transvaginal ultrasound (TVU) in the past year.

The Pelvic Organ Prolapse Quantification (POP-Q) system uses certain anatomical references such as the hymen, anterior vaginal wall, posterior vaginal wall, total vaginal length, urogenital hiatus, perineal body and cervix or vaginal apex as guiding points. All these references are expressed in $\mathrm{cm}$ and measured in proximal (above) or distal (below) in relation to the hymen and are designated as negative or positive respectively. Four prolapse stages from I to IV are established in which the fundamental considerations are the prolapse guiding points and their relation to the hymen expressed in $\mathrm{cm}$ and the total length of the vagina. ${ }^{18}$

Patients were excluded if they had UV-POP with a history of abnormal uterine bleeding, a pathological Pap smear or a history of cervical dysplasias or premalignant endometrial lesions, a TVU with an endometrial line greater than $10 \mathrm{~mm}$, a history of malignant ovarian tumours, use of tamoxifen or hormone replacement therapy, and those who did not give their consent for the study.

Out of a total of 133 patients assisted by the Unit team during the study period, 110 women (82.7\%) were selected in accordance with the inclusion criteria, and 23 patients (17.3\%) were excluded. Of the 23 cases excluded, 11 had a history of genital haemorrhage with premenopausal (three cases) or postmenopausal (eight cases) metrorrhagia, five patients had been diagnosed with cervical dysplasia or squamous intraepithelial lesion (SIL), four of whom were low-grade SIL (L-SIL) and 1 was high-grade SIL (H-SIL), five women had an endometrial line ultrasound measurement greater than $10 \mathrm{~mm}$, and two cases had had clinical and ultrasound diagnoses of adnexial tumour.

The vaginal repair surgery was performed by the same team in all cases. All patients underwent a $\mathrm{VH}$ associated with vaginal repair surgery. Vaginal apex suspension was performed to the uterosacral ligaments in all patients in accordance with the McCall culdoplasty technique. ${ }^{19}$

In cases with coexisting stress urinary incontinence, the middleurethral sling (MUS) technique was associated. ${ }^{20,21}$ All extracted uteri were sent for histopathological study. 
The following histopathological variables were analysed: presence of endometrial atrophy, endometrial hyperplasia with and without atypia, endometrial cancer, leiomyoma, focal and diffuse adenomyosis, chronic endocervicitis, L-SIL and H-SIL, as well as cervical carcinoma.

The statistical analysis was performed using the Excel 2013 Microsoft Office spreadsheet. For the qualitative variables in the cases where pathologies were detected, a frequency calculation was performed and expressed as absolute frequencies and relative percentage frequencies. For the quantitative variables, the mean, the standard deviation and range were calculated.

\section{RESULTS}

The mean age was 64 years old with a standard deviation of \pm 8.84 , with an age range between 46 and 83 years. The mean body mass index (BMI) was $26.56 \mathrm{~kg} / \mathrm{m}^{2}$ with a standard deviation of \pm 3.23 , with a range between 20.1 and $33.9 \mathrm{~kg} / \mathrm{m}^{2}$. Most of the patients (85.5\%) were postmenopausal (Table 1). None of the patients had family history of endometrial cancer. Smoking was observed in $21.8 \%$ of cases. Hypertension was observed in $16,3 \%$ and diabetes in $11 \%$. All women presented cystocele associated with hysterocele, while in $13.6 \%$ of them it was associated with high rectocele, and with enterocele in 1.8\% (Table 1). 4.5\% required a MUS technique.

Regarding the hysterocele stage according to POP-Q, 20\% was stage II, 51.8\% stage III and 28.2\% stage IV (Table 2).

As to the histopathological findings, $78.2 \%$ of cases did not have any pathology whatsoever. Amongst patients with endometrial pathology, 11 cases (10\%) exhibited hyperplasia without atypia and $12(10.9 \%)$ presented endometrial polyp without atypia. No cases of endometrial hyperplasia with atypia were observed. In some patients, an associated benign myometrial pathology was observed, such as uterine leiomyoma in $25.5 \%$, and focal and diffuse adenomyosis in $23.6 \%$ of cases (Table 3). In regard

\begin{tabular}{|l|l|l|}
\hline Table 1. Results & $\begin{array}{l}\text { Absolute } \\
\text { frequency }\end{array}$ & $\begin{array}{l}\text { Relative } \\
\text { frequency (\%) }\end{array}$ \\
\hline Premenopause & 16 & $14.5 \%$ \\
\hline Postmenopause & 94 & $85.5 \%$ \\
\hline Associated cystocele & 110 & $100 \%$ \\
\hline Associated high rectocele & 15 & $13.6 \%$ \\
\hline Associated enterocele & 2 & $1.8 \%$ \\
\hline Bilateral adnexectomy & 2 & $1.8 \%$ \\
\hline Associated MUS surgery & 5 & $4.5 \%$ \\
\hline Hysterocele & 110 & $100 \%$ \\
\hline MUs: Middle-urethral sling & & \\
\hline
\end{tabular}

to malignant pathology, only one $(0.9 \%)$ of the patient exhibited endometrial cancer, and none of the patients showed a malignant or pre-malignant pathology of the cervix or ovaries (Table 3). The ovaries were included in only two cases (1.8\%) during the surgery with normal histological findings.

One case of endometrial cancer was found in a 71-year-old woman with stage IV hysterocele according to POP-Q, asymptomatic, with TVU showing a $1 \mathrm{~mm}$ endometrial line, who underwent a VH and bilateral adnexectomy. The histopathological result reports a moderately differentiated adenocarcinoma that extensively infiltrates the cervix and the myometrium as far as the serosa (stage II - 2009 FIGO). Both annexes had a normal histopathological examination.

\section{DISCUSSION}

This study estimated the prevalence of malignant and premalignant uterine pathology in patients with UV-POP who

\begin{tabular}{|l|l|l|}
\hline Table 2. Hysterocele stage \\
\hline Hysterocele stage & $\begin{array}{l}\text { Absolute } \\
\text { frequency }\end{array}$ & $\begin{array}{l}\text { Relative } \\
\text { frequency (\%) }\end{array}$ \\
\hline POP-Q Stage II & 22 & $20 \%$ \\
\hline POP-Q Stage III & 57 & $51.8 \%$ \\
\hline POP-Q Stage IV & 31 & $28.2 \%$ \\
\hline POP-Q: Pelvic Organ Prolapse Quantification \\
\hline
\end{tabular}

Table 3. Histopathological findings

\begin{tabular}{|l|l|}
\hline $\begin{array}{l}\text { Absolute frequency } \\
(\mathrm{n}=110)\end{array}$ & $\begin{array}{l}\text { Relative } \\
\text { Frequency (\%) }\end{array}$ \\
\hline
\end{tabular}

\begin{tabular}{|l|l|l|}
\hline Uterus & \multicolumn{2}{l|}{} \\
\hline Leiomyomas & 28 & $25.45 \%$ \\
\hline Adenomyosis & 26 & $23.63 \%$ \\
\hline Endometrial atrophy & 78 & $70.9 \%$ \\
\hline EH without atypia & 11 & $10 \%$ \\
\hline EH with atypia & 0 & 0 \\
\hline Polyp without atypia & 12 & $10.9 \%$ \\
\hline Endometrial cancer & 1 & $0.9 \%$ \\
\hline Cervix & \multicolumn{2}{l|}{} \\
\hline Chronic EC & 45 & $40.9 \%$ \\
\hline Low-grade SIL & 0 & 0 \\
\hline High-grade SIL & 0 & 0 \\
\hline Cervical cancer & 0 & 0 \\
\hline Ovaries & 2 & $1.8 \%$ \\
\hline Normal & 0 & 0 \\
\hline Pathological & \multicolumn{2}{l|}{} \\
\hline $\begin{array}{l}\text { EH: Endometrial hyperplasia, EC: Endocervicitis, SIL: Squamous } \\
\text { intraepithelial lesion, n: Number }\end{array}$ &
\end{tabular}


underwent VH. All the patients included were asymptomatic, with normal TVU and Pap smears. The prevalence of endometrial cancer was $0.9 \%$ and that of cervical cancer was $0 \%$.

However, the inclusion of all precancerous conditions had a prevalence of $21.8 \%$. The premalignant lesions that were observed within the endometrium were hyperplasia and polyps without atypia. No case of atypia was observed. A lesional association with leiomyoma and adenomyosis of approximately $25 \%$ was found.

This makes it necessary to consider the importance of a clinical examination and a TVU at a time very close to the surgical procedure lest a detectable pathology is found only after surgery. Anyway, surgical behaviour would not vary in the cases analysed.

According to international literature, the incidence of malignant and premalignant endometrial pathology in asymptomatic women who undergo hysterectomy due to UV-POP ranges between 0.7 and $4.2 \%$. ${ }^{16,17,22,23}$

In a retrospective study ${ }^{16}$ the authors included 644 women, 421 of whom were postmenopausal with asymptomatic POP, with 11 patients found to have an organic endometrial pathology (2.6\%). As to these cases, only one case of endometrial cancer and 10 cases of hyperplasia were observed.

In another retrospective study ${ }^{17}$ unsuspected endometrial cancer was found in four cases (0.8\%) out of 517 asymptomatic patients who underwent $\mathrm{VH}$, not to mention the high incidence of hyperplasia.

In another retrospective study, ${ }^{22}$ three cases of premalignant and malignant endometrial pathology were observed in 456 asymptomatic patients $(0.7 \%)$.

These three studies include women with asymptomatic UV POP with no preoperative endometrial assessment.

\section{CONCLUSIONS}

The conclusion is that it is necessary to assess the endometrium before POP surgery by means of TVU followed by an endometrial biopsy in cases of thickened endometrium.

In a retrospective study where they considered the preoperative assessment, Grigoriadis et al. ${ }^{23}$ found 14 histopathological abnormalities in the uteri of 333 asymptomatic women who underwent VH (4.2\%) and concluded that the incidence of premalignant and malignant gynaecological pathology is low but not negligible.

There is no agreement on the most appropriate course of action in the cases of asymptomatic patients with a thickened endometrium..$^{24}$ In a cohort study ${ }^{25}$ the authors conclude that in asymptomatic postmenopausal women with an endometrium $\geq 11 \mathrm{~mm}$, an endometrial biopsy should be performed.

Our research considered the value of the TVU, especially in order to assess the risk of unexpected premalignant and malignant endometrial pathology. One of the limitations of our study is that the number of patients analysed is relatively small, but it may be useful for future research in which other risk factors such as smoking and medical comorbidities are considered in addition to age and BMI. One of the strengths of this study is the prospective and cross-sectional design, in addition to the assessment of the risk of not diagnosing a premalignant and malignant pathology of the uterus through clinical assessment and Pap and TVU studies in the preoperative period.

It may be concluded that the prevalence of premalignant and malignant uterine pathology is low, at $0.9 \%$. This leads to the reinforcement of the idea of the importance of a clinical history with no abnormal uterine bleeding, endometrial assessment by TVU close to the date of the surgery and cytological assessment of the cervix through a Pap smear which will allow adequate preoperative diagnosis in the case of a hysterocele. A briefing regarding the risk of premalignant and malignant pathology should be included in the information provided during the preoperative period in the form of a consent document. When conservative management, such as a surgical procedure for uterine fixation (hysteropexy) is chosen, it is imperative to make a careful preoperative assessment to rule out -with the exceptions shown by all studies- a precancerous or cancerous condition of the uterus.

\section{Ethics}

Ethics Committee Approval: The study was approved by the Ethics Committee of the Hospital de Clínicas of Medical School of Montevideo, University of the Republic (Date 2017, March 5).

Informed Consent: All the participants signed a consent document after being briefed about the study.

Peer-review: Editorial choice.

\section{DISCLOSURES}

Conflict of Interest: The authors have no conflicts of interest.

Financial Disclosure: The authors declared that this study has received no financial support.

\section{REFERENCES}

1. Beck RP, McCormick S, Nordstrom L. A 25-year experience with 519 anterior colporraphy procedures. Obstet Gynecol 1991; 78: 1011-8.

2. Samuelsson EC, Victor FT, Tibblin G, Svardsudd KF. Signs of genital prolapse in a Swedish population of women 20 to 59 years of age 
and possible related factors. Am J Obstet Gynecol 1999; 180: 299305.

3. Slieker-ten Hove MC, Pool-Goudzwaard AL, Eijkemans MJ, SteegersTheunissen RP, Burger CW, Vierhout ME. The prevalence of pelvic organ prolapse symptoms and signs and their relation with bladder and bowel disorders in a general female population. Int Urogynecol J Pelvic Floor Dysfunct 2009; 20: 1037-45.

4. Nyggard I, Bradley C, Brandt D. Pelvic organ prolapse in older women: prevalence and risk factors. Obstet Gynecol 2004; 104: 48997.

5. Grigoriadis T, Athanasiou S, Giannoulis G, Mylona SC, Lourantou D, Antsaklis A. Translation and psychometric evaluation of the Greek short forms of two condition specific quality of life questionnaire for women with pelvic floor disorders: PFDI-20 and PFIQ-7. Int Urogynecol J 2013; 24: 2131-44.

6. Castillo-Pino E. Prolapso de los órganos pélvicos. In: Castillo E, Malfatto G, Pons J, eds. Uroginecologia y Disfunciones del Piso Pélvico. 2007; 273-86. Primera edición. Montevideo: Oficina del Libro FEFMUR.

7. Sotero G, Sosa C, Dominguez A, Martinez J. Via de la histeretomia: flujograma de decisiones. AGO 2003; 41: 17-20.

8. Kovac SR. Guidelines to determinate the route of hysterectomy. Obstet Gynecol 1995; 85: 18-23.

9. Cosson M, Querleu D, Subtil D, Switala I, Buchet B, Crepin G. The feasibility of vaginal hysterectomy. Eur J Obstet Gynecol Reprod Biol 1996; 64: 95-9.

10. Lucero M, Shah AD. Vaginal hysterectomy for the prolapsed uterus. Clin Obstet Gynecol 2010; 53: 26-39.

11. Temkin O. Soranus`s Gynecology. 1956; 207. Baltimore: The Johns Hopkins University Press.

12. Sauter: Die giinzliche Extirpation der Gebarmutter ohne selbst, entstandenen oder Riinstlich bewirkter Vorfall vorgenommen und gliicklich vollfiihrt mit niiherer Anleitung, wie diese Operation gemacht werden kann. Constanz, 1822.

13. Hefni MA, El-Toukhy TA. Long-term outcomes of vaginal sacrospinous colpopexy for marked uterovaginal and vault prolapse. Eur J Obstet Gynecol Reprod Biol 2006; 127: 257-63.

14. Romanzi LJ, Tyagi R. Hysteropexy compared to hysterectomy for uterine prolapse surgery: does durability differ? Int Urogynecol J 2012; 23: 625-31.
15. Dietz V, van der Vaart $\mathrm{CH}$, van der Graaf $\mathrm{Y}$, Heintz P, Schraffordt Koops SE. One year follow-up after sacrospinous hysteropexy and vaginal hysterectomy for uterine descent: a Randomized study. Int Urogynecol J 2010; 21: 209-16.

16. Frick AC, Walters MD, Larkin KS, Barber MD. Risk of unanticipated abnormal gynecologic pathology at the time of hysterectomy for uterovaginal prolapse. Am J Obstet Gynecol 2010; 202: 507.e1-4.

17. Renganathan A, Edwards R, Duckett JR. Uterus conservative prolapse surgery what is the chance of missing a malignancy? Int Urogynecol J 2010; 21: 819-21.

18. Bump RC, Mattiasson A, Bø K, et al. The standardization of terminology of female pelvic organ prolapse and pelvic floor dysfunction. Am J Obstet Gynecol 1996; 175: 10-7.

19. McCall ML. Posterior culdoplasty: surgical correction of enterocele during vaginal hysterectomy. A preliminary report. Obstet Gynecol 1957; 10: 595-602.

20. Ulmsten U, Petros P. Intravaginal slingplasty (IVS): an ambulatory surgical procedure for treatment of female urinary incontinence. Scand J Urol Nephrol 1995; 29: 75-82.

21. Delorme E. [Transobturator urethral suspension: mini-invasive procedure in the treatment of stress urinary incontinence in women]. Prog Urol 2001; 11: 1306-13.

22. Wan OY, Cheung RY, Chan SS, Chung TK. Risk of malignancy in women who underwent hysterectomy for uterine prolapse. Aust N Z J Obstet Gynaecol 2013; 53: 190-6.

23. Grigoriadis T, Valla A, Zacharakis D, Protopapas A, Athanasiou S. Vaginal hysterectomy for uterovaginal prolapse: what is the incidence of concurrent gynecological malignancy? Int Urogynecol J 2015; 26: 421-5.

24. Breijer MC, Peeters JA, Opmeer BC, et al. Capacity of endometrial thickness measurement to diagnose endometrial carcinoma in asymptomatic postmenopausal women: a systematic review and meta-analysis. Ultrasound Obstet Gynecol 2012; 40: 621-9.

25. Smith-Bindman R, Weiss E, Feldstein V. How thick is too thick? When endometrial thickness should prompt biopsy in postmenopausal women without vaginal bleeding. Ultrasound Obstet Gynecol 2004; 24: 558-65. 